\title{
The Studies on the Surface Organic Modification of Tourmaline Powder with Stearic Acid and Its Composite
}

\author{
Yingmo Hu \\ School of Materials Science and Technology, China University of Geosciences, Beijing, China \\ Email: huyingmo@163.com
}

Received 9 May 2014; revised 9 June 2014; accepted 25 June 2014

Copyright (C) 2014 by author and Scientific Research Publishing Inc. This work is licensed under the Creative Commons Attribution International License (CC BY). http://creativecommons.org/licenses/by/4.0/ c) (7) Open Access

\begin{abstract}
Stearic acid modified tourmaline powder had been investigated to improve the compatibility and dispersed stability between tourmaline and polymer matrix. The experimental results indicated that the activation index was $100 \%$ and contact angle reached $120^{\circ}$ when the ratio of the ore slurry is 5:50, the dosage of stearic acid and $p$-toluenesulfonic acid is $10 \%$ and $0.5 \%$ (of tourmaline powder's quantity) respectively with reaction at $80^{\circ} \mathrm{C}$ for $6.0 \mathrm{~h}$, and the modified tourmaline exhibited an excellent hydrophobic property. The introduction of stearic groups reduced the reunion of tourmaline particles clearly and improved the dispersivity in polymers, and the amount of negative ions released of modified tourmaline increased obviously for both modified tourmaline powders and its composite with polyamide- 66 compared to the unmodified tourmaline. Moreover, the structure of modified tourmaline was also characterized by means of Fourier Transform infrared spectroscopy, X-ray diffraction, thermal gravimetric analysis, scanning electron microscope.
\end{abstract}

\section{Keywords}

Tourmaline, Stearic Acid, Surface Modification, Negative Ion, Composites

\section{Introduction}

Tourmaline is a particular mineral and attracting widespread attentions for its piezoelectric and pyroelectric characteristics since which was discovered by E. Rieche [1] in the early nineteenth century. It also can generate the oxygen ions [2] [3] and far-infrared electromagnetic radiation [4] [5] to benefit human health. If tourmaline can be loaded onto polymeric fibers or other composites, its applications can be further expanded to functional 
health-care products or special light \& electrical functional materials [6]-[8].

Generally, tourmaline powders and polymers are in poor compatibility due to their different surface properties. The poor dispersity of tourmaline, especially in a non-polar polymer matrix, can always reduce the mechanical properties, and thus leading to low overall performance of the material [9]. Therefore, organic surface modifications are requisite to improve the compatibility and dispersion stability between tourmaline and the polymer-resin matrix [10]. Recently, the organic modification of tourmaline is very active and receiving the attentions of scientists and engineers [11] [12]. Accordingly, some related applications have been advanced, e.g. the far-infrared radiation and negative oxygen ions released functional materials [13] [14].

In this study, we report our investigation on the reactivity between tourmaline powders and stearic acid, in which the activation index and contact angle are the two major experimental parameters that we concerned on, and the tourmaline/PA-66 composites combined with a polar polymer polyamide-66. The structure of modified tourmaline was characterized, and the amounts of negative ions released by modified tourmaline powders and its composite have been measured quantitatively.

\section{Experimental Procedures}

\subsection{Materials and Instruments}

Tourmaline powder with diameters of $d_{50} 1.75 \mathrm{~mm}$ and $d_{97} 5.23 \mathrm{~mm}$ (purity 98\%) was purchased from Yanxin Mineral Company Limited, Hebei, China; stearic acid (analytical reagent) was obtained from West Long Chemical Company; and liquid paraffin (chemical pure), ethanol (analytical reagent), acetone (analytical reagent), toluene (analytical reagent) and $p$-toluenesulfonic acid (analytical reagent) were purchased from Beijing Chemical Reagent Factory, and polyamide-66 was purchased from Pindingshan Shenma Engineering Plastics Company Limited.

The testing devices included a Perkin Elmer Spectrum 100 Fourier transform infrared (FTIR) spectrometer (Shanghai Company) and a Rigaku D/max-rA 12 kw X-ray diffractometer (XRD) (Japan). Scanning electron microscope (SEM) images were observed on a Hitachi Model S-450 scanning electron microscope, and the DSA100M optical measurement (Zhongchen Digital Technology \& Instrument Company, Shanghai) was used for the measurements of the contact angles. Thermal gravimetric analysis (TGA) was analyzed with Q500 Thermogravimetric Analyser (TA instrument Company, American); And the amount of negative ions released were measured on the AIC1000 negative ion concentration tester (Alphalab Company, American).

\subsection{Experimental Method of Stearic Acid Modified Tourmaline}

In a $100 \mathrm{ml}$ three-neck flask, $5 \mathrm{~g}$ of super-fine tourmaline powder and stearic acid in $50 \mathrm{ml}$ of toluene was stirred adequately, then $p$-toluenesulfonic acid was added into flask, reacted at $80^{\circ} \mathrm{C}$ for $5 \mathrm{~h}$. The samples were separated by centrifugation, washed three times with ethanol and acetone, and finally dried and ground prior to characterization.

\subsection{Characterization}

\subsubsection{The Measurement of Contact Angle}

The sample was pressed into a circle using a press, and distilled water was then dripped onto the surface of the sample to evaluate the contact angle using optical measurements. Each value was averaged over three tests.

\subsubsection{The Determination of the Activation Index}

The activation index of the modified tourmaline was determined according to the HG/T2567 standard (former Ministry of Chemical Industry). In a $100 \mathrm{ml}$ beaker, $1.0 \mathrm{~g}$ of modified tourmaline $\left(\mathrm{M}_{0}\right)$ in $50 \mathrm{ml}$ of water was stirred for $5 \mathrm{~min}$ and allowed to stand statically for $5 \mathrm{~h}$. The turbid solution in the middle of the beaker turned clear, and the powders floating on top of the solution were collected, dried and weighed as $\mathrm{M}_{1}$. The activation index was calculated as follows:

$$
\text { Activation index }(H)=\left[\mathrm{M}_{1} / \mathrm{M}_{0}\right] \times 100 \%
$$




\section{Results and Discussion}

\subsection{The Influence of the Reaction Conditions on the Modification of Tourmaline Powder}

The modification effect of tourmaline powder under various conditions such as the quantity of stearic acid and $p$-toluenesulfonic acid, reaction temperature and time were studied by focusing on the experimental parameters of the activation index and contact angle.

\subsubsection{The Influence of the Amount of Stearic Acid}

The influence of the amount of stearic acid is shown in Figure 1. Both curves indicate that the activation index and contact angle of modified tourmaline increase sharply at first and then trend to fall a bit with increasing of the amount of stearic acid, and reached their maximum values when the weight ratios of stearic acid to tourmaline was 0.5:5.

\subsubsection{The Influence of the Reaction Temperature}

The influence of the reaction temperature is displayed in Figure 2. The results showed that the activation index and contact angle of modified tourmaline first increase and then decrease quickly with the raise of reaction temperature. The maximum values appeared at $80^{\circ} \mathrm{C}$. Therefore, the temperature of $80^{\circ} \mathrm{C}$ was selected as the optimum reaction temperature.

\subsubsection{The Influence of the Reaction Time}

The influence of reaction time on the modification of tourmaline is plotted in Figure 3. The both curves demonstrated that the activation index and contact angle of modified tourmaline first rise rapidly and then drop with prolonging the reaction time, and reach their maximum values at $6 \mathrm{~h}$. Therefore, $6 \mathrm{~h}$ was chosen as the optimum reaction time for further experiments.

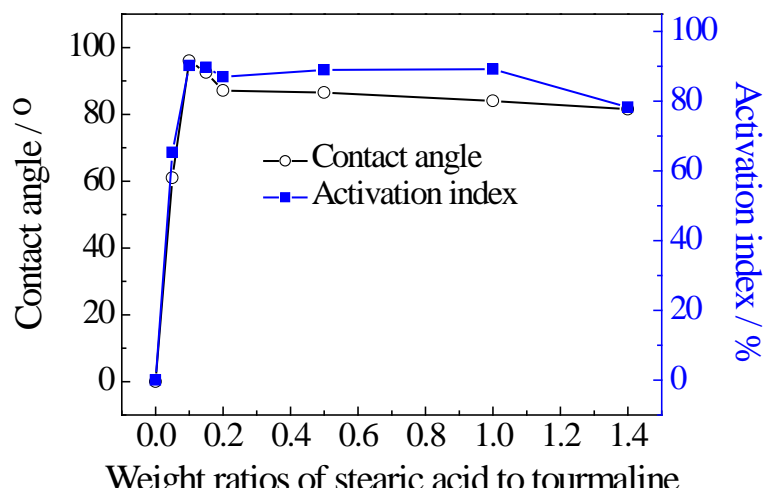

Figure 1. Effect of weight ratios of stearic acid to tourmaline.

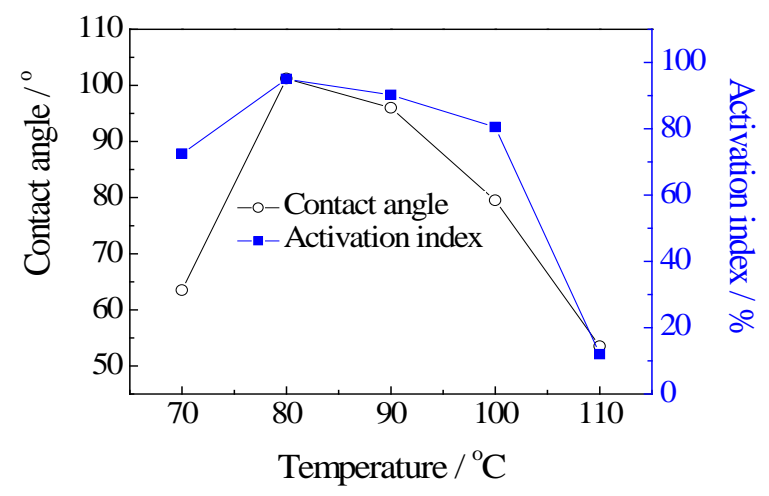

Figure 2. Effect of temperature. 


\subsubsection{The Influence of the Amount of $p$-Toluenesulfonic Acid}

The influence of the amount of $p$-toluenesulfonic acid on the modification of tourmaline is presented in Figure 4. Both the activation index and contact angle of the modified tourmaline exhibit similar trends with respect to the amount of $p$-toluenesulfonic acid and reach their maximum values at $0.5 \%$ (of tourmaline powder's quantity). Therefore, $0.5 \%$ was selected as the optimal amount of $p$-toluenesulfonic acid for further experiments.

\subsubsection{The Influence of the Mass Ratios of the Ore Slurry}

The mass ratios of tourmaline to solvent also have impact on the modification of tourmaline, which is illustrated in Figure 5. The curves indicated that the activation index and contact angle of the modified tourmaline sharply increase with increasing the amounts of tourmaline before the mass ratio of tourmaline to solvent reaches 5:50. After this point, the activation index and contact angle level off and then decrease with further increases in the mass ratio, because of the reaction efficiency of tourmaline with stearic acid has dropped for stearic acid could not contact with tourmaline sufficiently while the mass ratios of the ore slurry increased. The optimum mass ratio of tourmaline to solvent is therefore 5:50. The activation index of the modified tourmaline is $100 \%$ and its contact angle reaches $120^{\circ}$, which exhibit excellent hydrophobic properties.

\subsection{The Structural Characterization of Modified Tourmaline}

The structure of modified tourmaline was characterized by IR spectra, XRD analysis, SEM images and so on.

\subsubsection{IR Spectra}

Figure 6 shows the IR spectra of unmodified and modified tourmaline, in which the unmodified tourmaline [15] exhibits absorption bands at $3560 \mathrm{~cm}^{-1}$ (-OH group), $1270 \mathrm{~cm}^{-1}$ (B-O group) and $978 \mathrm{~cm}^{-1}$ (Si-O group). Compared with Figure 6(a), the IR spectrum of modified tourmaline (Figure 6(b)) shows new absorption bands of methyl $\left(2929 \mathrm{~cm}^{-1}\right)$, methylene $\left(2850 \mathrm{~cm}^{-1}\right)$ and carbonyl $\left(1642 \mathrm{~cm}^{-1}\right)$ groups, which indicates that stearic acid reacts with the hydroxyl groups on the surface of tourmaline to produce the stearate of tourmaline. The carbonyl

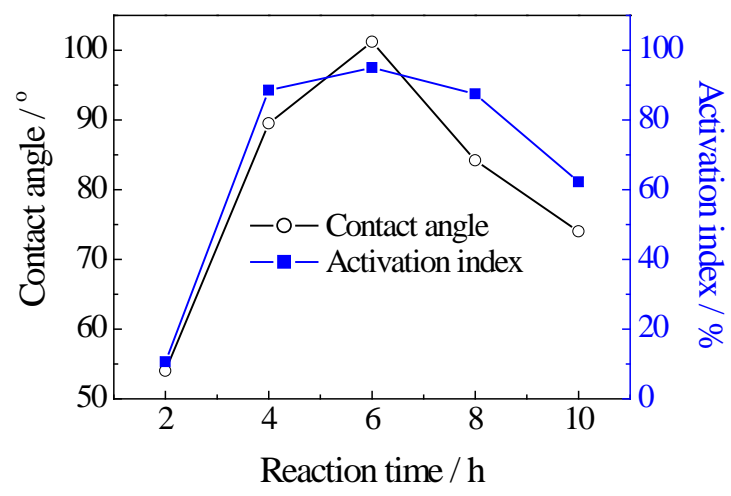

Figure 3. Effect of reaction time.

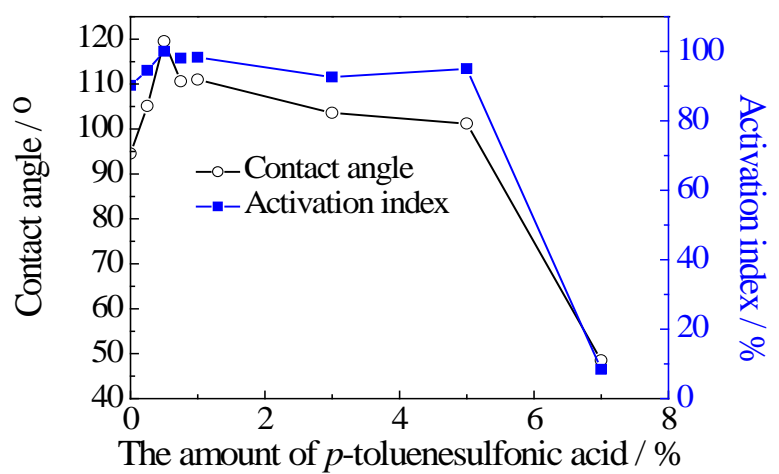

Figure 4. Effect of the amount of $p$-toluenesulfonic acid. 


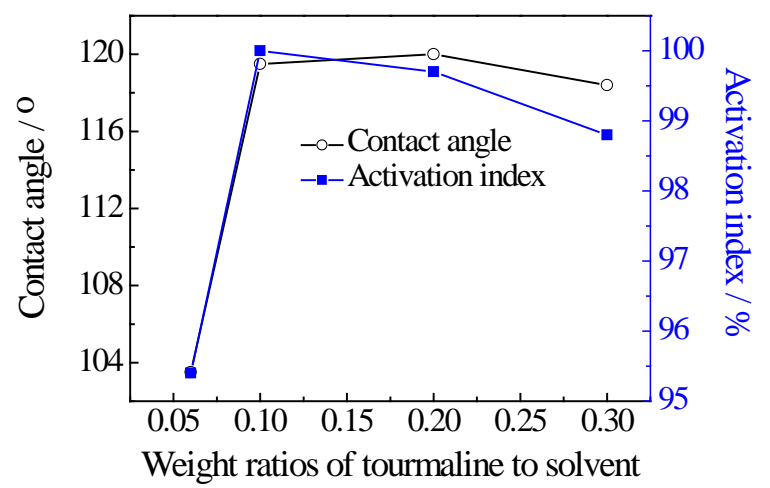

Figure 5. The influence of weight ratios of tourmaline to solvent.

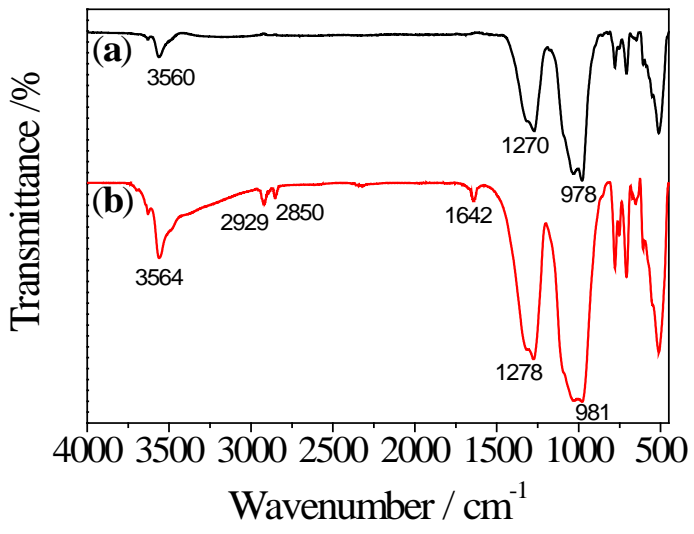

Figure 6. IR spectra of unmodified (a) and modified (b) tourmaline.

band exhibits a red shift because of the electric effect of the metal ions on the surface of tourmaline. Other peaks (e.g., the B-O and Si-O bands) are also red shifted for a few wave numbers and broadened. These results indicate that stearic groups were introduced onto the surface of the tourmaline by the reaction of stearic acid with tourmaline powder (Equation (1)), and therefore the hydrophobic properties of tourmaline were improved.

$$
\begin{aligned}
\mathrm{CH}_{3}\left(\mathrm{CH}_{2}\right)_{15} \mathrm{CH}_{2} \mathrm{COOH} & +\mathrm{HO} \text { Tourmaline } \\
& \longrightarrow \mathrm{CH}_{3}\left(\mathrm{CH}_{2}\right)_{15} \mathrm{CH}_{2}-\stackrel{\mathrm{O}}{\mathrm{C}}-\mathrm{O} \text {-Tourmaline }
\end{aligned}
$$

\subsubsection{XRD Patterns}

The XRD patterns of unmodified and modified tourmaline are shown in Figure 7(a) and Figure 7(b), respectively. The major peaks of unmodified tourmaline appeared at $2 \theta$ angles of $13.8^{\circ}, 21.0^{\circ}, 22.0^{\circ}, 25.5^{\circ}, 26.7^{\circ}, 30.3^{\circ}$, $34.7^{\circ}, 44.3^{\circ}, 47.1^{\circ}, 55.3^{\circ}, 57.7^{\circ}, 61.5^{\circ}$ and $63.9^{\circ}$. The major peaks of the modified tourmaline were located at the same $2 \theta$ angles with no other phases being detected. These results demonstrate that the modifications of tourmaline with stearic acid only altered the surface properties of tourmaline, and the crystal structure of tourmaline remains unchanged.

\subsubsection{SEM Images}

The SEM images of unmodified and modified tourmaline are presented in Figure 8. It is obviously to found some conglomeration in unmodified tourmaline particles (Figure 8(a)), while no agglomerates were observed in modified tourmaline particles (Figure 8(b)). These results are attributable to the strong polar surfaces of the tourmaline particles before modification, which enabled the easy conglomeration of the particles. In addition, 
the surface polarity of the tourmaline was reduced after the organic modification, thereupon the surface energy was depressed, thus the dispersivity of the tourmaline particles was improved.

\subsubsection{TGA Curves}

Figure 9 showd the TGA curves of unmodified and modified tourmaline. The TGA curve of modified tourmaline (Figure 9(b)) exhibits a significantly greater weight loss in the temperature range of $138^{\circ} \mathrm{C}-380^{\circ} \mathrm{C}$ compared with the unmodified tourmaline (Figure 9(a)). The organic chains introduced onto the surface of tourmaline particles decomposed easily in this temperature range, indicating that stearic acid had reacted with tourmaline resulting in the introduction of the hydrophobic alkyl chain, which also corresponded to the IR analysis.

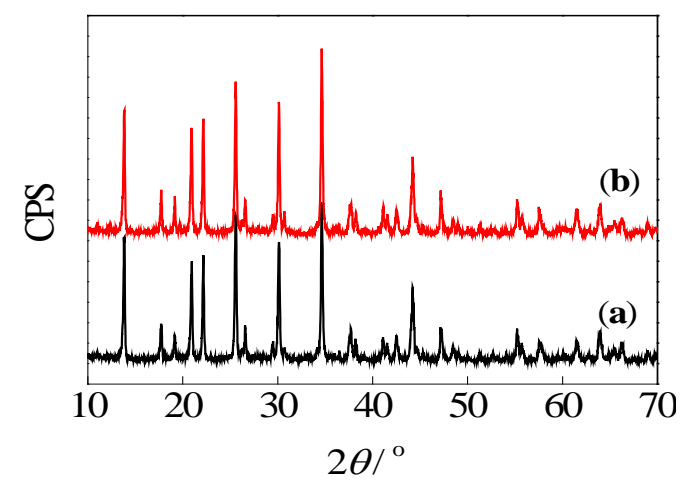

Figure 7. XRD spectra of unmodified (a) and modified (b) tourmaline.
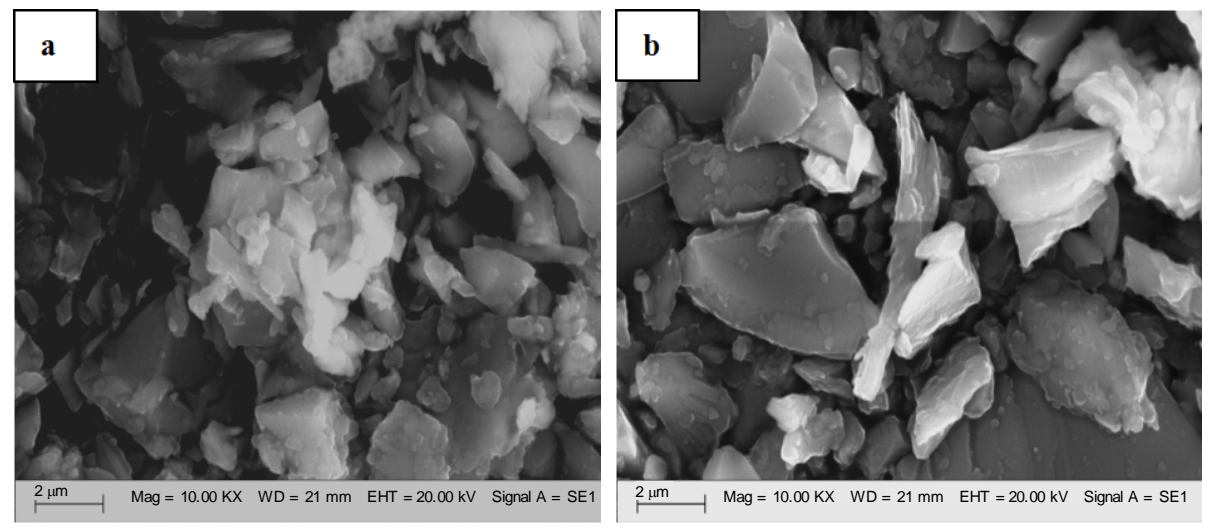

Figure 8. SEM images of unmodified (a) and modified (b) tourmaline.

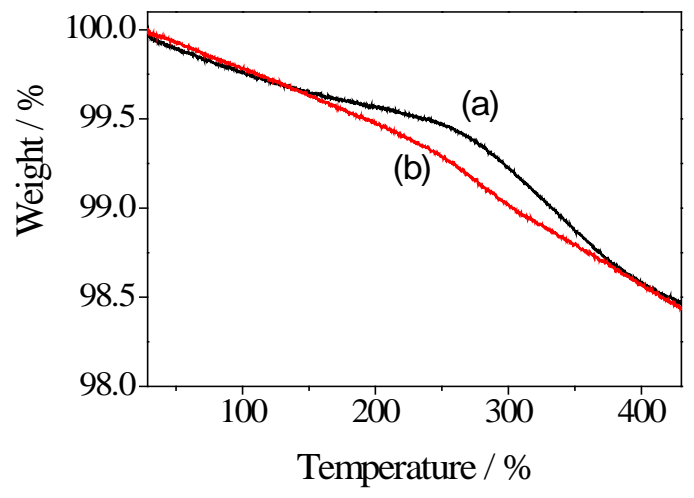

Figure 9. The TGA curves of unmodified (a) and modified (b) tourmaline. 


\subsection{Performance Characterization}

\subsubsection{The Mensuration of the Negative Ions}

The amount of negative ions released from the unmodified and modified tourmaline was listed in Table 1. From the data in the table, the amount of negative ions released by tourmaline modified with stearic acid is more than 2.69 times greater than that released by the unmodified tourmaline. These results indicate that the surface energy of the organic-modified tourmaline particles was reduced, aggregation of the particles decreased and the surface area of tourmaline particle increased, which resulted in an increased amount of released negative ions.

\subsubsection{The Dispersancy of Tourmaline in Polyamide-66 (PA-66)}

In order to evaluate the dispersancy of modified tourmaline in a polymer, the composites of modified tourmaline and unmodified tourmaline with polyamide-66 (PA-66) were prepared, and characterized by SEM images and by the detection of the release of negative ions.

1) The preparation of tourmaline/PA-66 composites

Tourmaline (5\% of PA-66 dosage) was added to a flask that contained PA-66 dissolved in dimethyl sulfoxide (DMSO) and stirred for $40 \mathrm{~min}$ at $170^{\circ} \mathrm{C}$. The mixture was cooled and poured into the distilled water with stirred quickly, then filtrated and washed three times with distilled water, dried to get the tourmaline/PA-66 composite.

2) SEM analysis of tourmaline/PA-66 composites

Figure 10 indicates that the unmodified tourmaline images display some aggregation matrix in PA-66, whereas the modified tourmaline images show that the sample was homogeneously dispersed in PA-66. The excellent dispersion in PA-66 of modified tourmaline was because that the stearic groups were introduced onto the surface of tourmaline by the reaction of stearic acid with tourmaline powder (Equation (1)), which favored its dispersion in polymer. This result is consistent with the previously discussed experimental results of the activation index and contact angle of modified tourmaline.

3) The examination of amount of negative ions released of tourmaline/PA-66 composites

The amount of negative ions released by tourmaline/PA-66 composites is shown in Table 2. The data in the table reveal that the amount of negative ions released from modified tourmaline/PA-66 composite is obviously beyond that released from the tourmaline/PA-66 composite. These results indicated that the dispersancy of tourmaline was the crucial factor that affects the amount of negative ions released.

\section{Summary}

The activation index of modified tourmaline powder can reach $100 \%$ when tourmaline-to-solvent mass ratios is
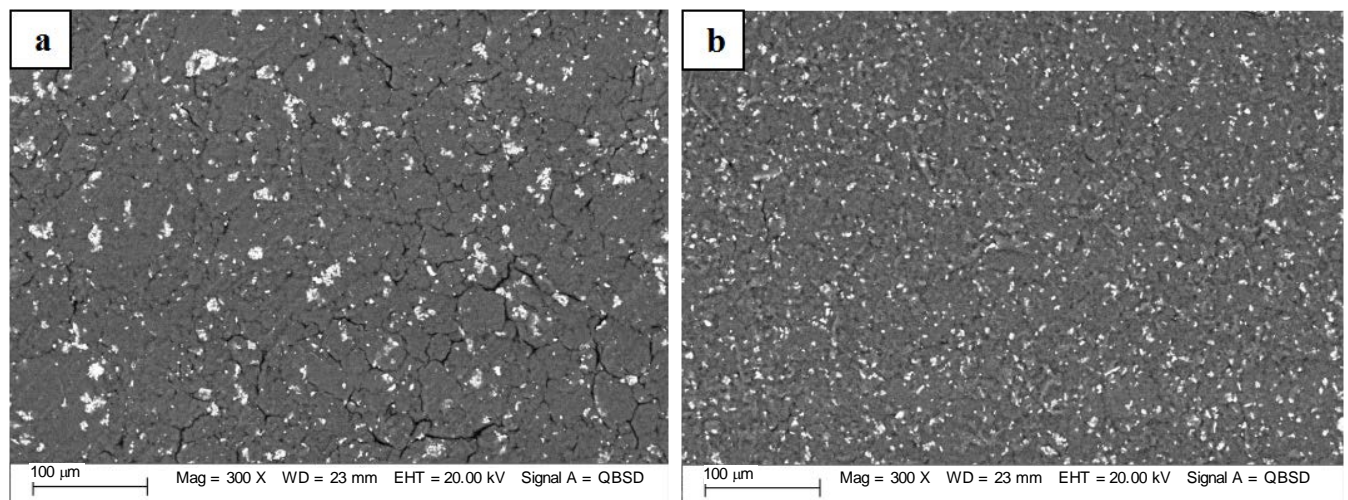

Figure 10. The SEM images of unmodified tourmaline/PA-66 (a) and modified tourmaline/PA-66 (b) composites.

Table 1. The amount of negative ions released by unmodified and modified tourmaline.

\begin{tabular}{cc}
\hline Sample & The amount of negative ions (ions $/ \mathrm{cm}^{3}$ ) \\
\hline Tourmaline & 320 \\
Modified tourmaline & 860 \\
\hline
\end{tabular}


Table 2. The amount of negative ions released by composites of tourmaline/PA-66 and modified tourmaline/PA-66.

\begin{tabular}{cc}
\hline Composites & The amount of negative ions $\left(\right.$ ions $\left./ \mathrm{cm}^{3}\right)$ \\
\hline 5\% tourmaline/PA-66 & 300 \\
$5 \%$ modified tourmaline/PA-66 & 500
\end{tabular}

5:50, the dosage of stearic acid and $p$-toluenesulfonic acid are $10 \%$ and $0.5 \%$ (of tourmaline powder's quantity) respectively, at $80^{\circ} \mathrm{C}$ for $6.0 \mathrm{~h}$. The contact angle of the modified tourmaline is $120^{\circ}$, which exhibits excellent hydrophobic properties for the modified tourmaline. The experimental results indicated that the stearic groups were introduced onto the surface of tourmaline by transesterification of the hydroxyl groups at the surface of the tourmaline particles with stearic acid, which improved the hydrophobic properties of tourmaline surface while keeping its crystal configuration unchanged, and reduced the reunion of tourmaline particles clearly and improved the dispersivity in polymers. And the amount of negative ions released by modified tourmaline increased obviously for both modified tourmaline powders and its composite with PA-66 compared to the unmodified tourmaline. The results offered an importance to prepare functional tourmaline composites.

\section{Acknowledgements}

This work is supported by the National Natural Science Foundation of China (No. 51072187, No. 51372233).

\section{References}

[1] Rieche, E. (1913) The Molecular Theory of the Piezo-Electricity of Tourmaline. Archives des Sciences Physiques et Naturelles, 36, 101-112.

[2] Jiang, K., Sun, T.H., Sun, L.N. and Li, H.B. (2006) Adsorption Characteristics of Copper, Lead, Zinc and Cadmium Ions by Tourmaline. Journal of Environmental Sciences, 18, 1221-1225. http://dx.doi.org/10.1016/S1001-0742(06)60066-1

[3] Eduardo, G., Sergio, A., Christian, F.L., Paolo, C., Pietro, V., Valier, G. and Maarten, L. (2011) Mineralogical and Chemical Variability of Fluvial Sediments 2. Suspended-Load Silt (Ganga-Brahmaputra, Bangladesh). Earth and Planetary Science Letters, 302, 107-120. http://dx.doi.org/10.1016/j.epsl.2010.11.043

[4] Ekosse, G.I.E. (2010) Kaolin Deposits and Occurrences in Africa: Geology, Mineralogy and Utilization. Applied Clay Science, 50, 212-236. http://dx.doi.org/10.1016/j.clay.2010.08.003

[5] Xu, H.Y., Prasad, M. and Liu, Y. (2009) Schorl: A Novel Catalyst in Mineral-Catalyzed Fenton-Like System for Dyeing Wastewater Discoloration. Journal of Hazardous Materials, 165, 1186-1192. http://dx.doi.org/10.1016/j.jhazmat.2008.10.108

[6] Liu, S.M., Li, D.C., Hu, W.T., Qin, G.Q. and Li, L.F. (2008) Ion-Beam Deposition of Tourmaline Film on Glass. Journal of Non-Crystalline Solids, 354, 1444-1446. http://dx.doi.org/10.1016/j.jnoncrysol.2006.11.052

[7] Park, S.H. and Bandaru, P.R. (2010) Improved Mechanical Properties of Carbon Nanotube/Polymer Composites through the Use of Carboxyl-Epoxide Functional Group Linkages. Polymer, 51, 5071-5077. http://dx.doi.org/10.1016/j.polymer.2010.08.063

[8] Lvov, Y. and Abdullayev, E. (2013) Functional Polymer-Clay Nanotube Composites with Sustained Release of Chemical Agents. Progress Polymer Science, 38, 1690-1719. http://dx.doi.org/10.1016/j.progpolymsci.2013.05.009

[9] Zhang, J., Ju, S., Jiang, D. and Peng, H.X. (2013) Reducing Dispersity of Mechanical Properties of Carbon Fiber/ Epoxy Composites by Introducing Multi-Walled Carbon Nanotubes. Composites Part B, 54, 371-376. http://dx.doi.org/10.1016/j.compositesb.2013.05.046

[10] Bhui, D.K. and Misra, A. (2012) Synthesis of Worm Like Silver Nanoparticles in Methyl Cellulose Polymeric Matrix and Its Catalytic Activity. Carbohydrate Polymers, 89, 830-835. http://dx.doi.org/10.1016/j.carbpol.2012.04.017

[11] Harald, G.D. (2010) The “Chessboard” Classification Scheme of Mineral Deposits: Mineralogy and Geology from Aluminum to Zirconium. Earth-Science Reviews, 100, 1-420. http://dx.doi.org/10.1016/j.earscirev.2009.10.011

[12] Jana, S., Saikia, A., Purkait, M.K. and Mohanty, K. (2011) Chitosan Based Ceramic Ultrafiltration Membrane: Preparation, Characterization and Application to Remove $\mathrm{Hg}(\mathrm{II})$ and $\mathrm{As}(\mathrm{III})$ Using Polymer Enhanced Ultrafiltration. Chemical Engineering Journal, 170, 209-219. http://dx.doi.org/10.1016/j.cej.2011.03.056

[13] Groat, L.A., Giuliani, G., Marshall, D.D. and Turner, D. (2008) Emerald Deposits and Occurrences: A Review. Ore 
Geology Reviews, 34, 87-112. http://dx.doi.org/10.1016/j.oregeorev.2007.09.003

[14] Liang, J.S., Wang, L.J., Xu, G.K., Meng, J.P. and Ding, Y. (2006) Far Infrared Radiation Property of Rare Earth Mineral Composite Materials. Journal of Rare Earths, 24, 281-283. http://dx.doi.org/10.1016/S1002-0721(07)60381-0

[15] Prasad, P.S.R. and Sarma, D.S. (2005) Study of Structural Disorder in Natural Tourmalines by Infrared Spectroscopy. Gondwana Research (Gondwana Newsletter Section), 8, 265-270. http://dx.doi.org/10.1016/S1342-937X(05)71125-4 
Scientific Research Publishing (SCIRP) is one of the largest Open Access journal publishers. It is currently publishing more than 200 open access, online, peer-reviewed journals covering a wide range of academic disciplines. SCIRP serves the worldwide academic communities and contributes to the progress and application of science with its publication.

Other selected journals from SCIRP are listed as below. Submit your manuscript to us via either submit@scirp.org or Online Submission Portal.
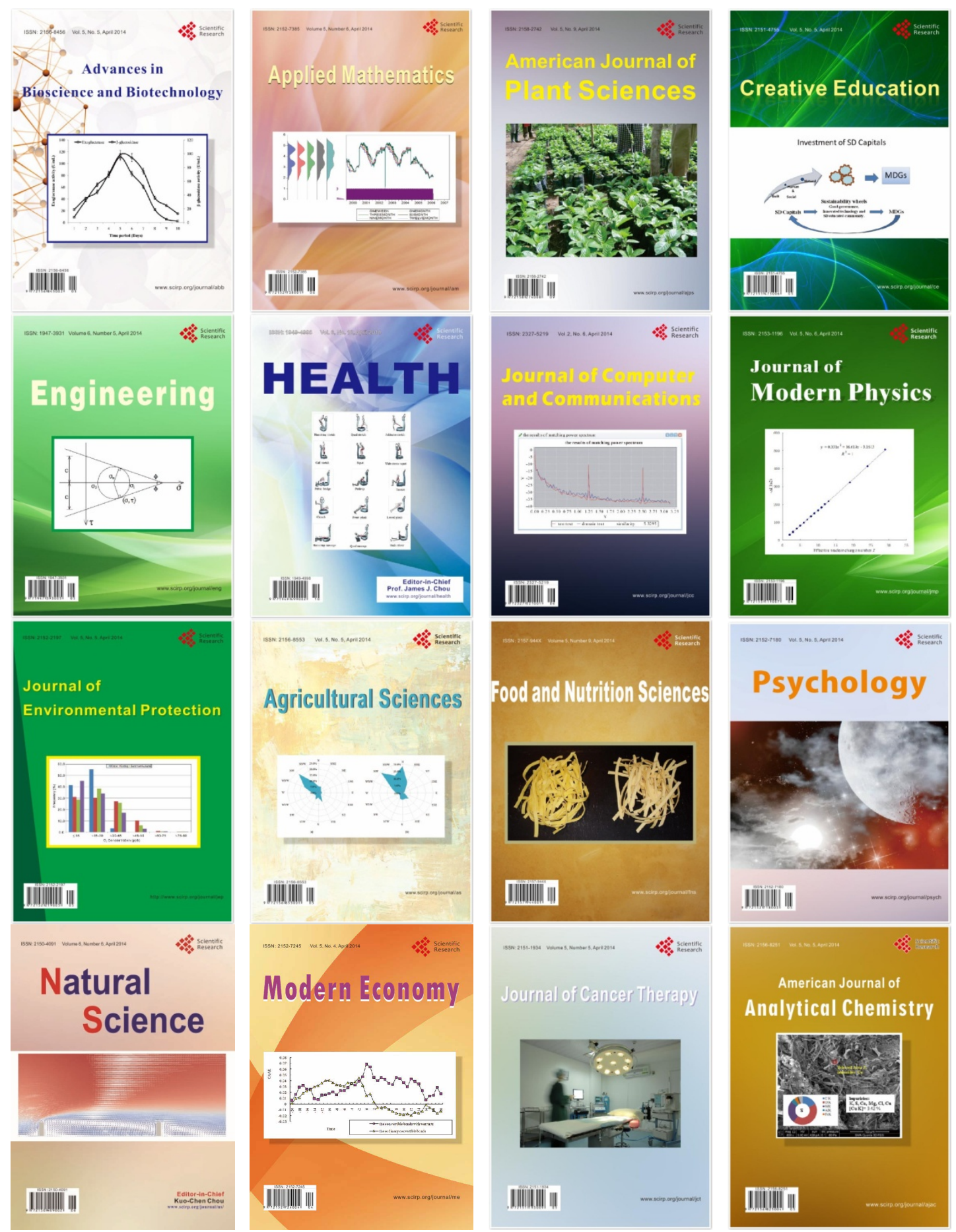